1 Centre for Behaviour Change, University College London, UK

2 Department of Behavioural Science and Health, University College London, UK

3 Department of Experimental Psychology, University College London, UK

s.michie@ucl.ac.uk Cite this as: BMJ 2020;371:m4171 http://dx.doi.org/10.1136/bmj.m4171 Published: 02 November 2020

\title{
The concept of "fatigue" in tackling covid-19
}

\section{Instead of using the concept of "fatigue" to understand a lack of adherence to covid-19 rules, we should focus on-and tackle-people's capability, opportunity, and motivation, say Susan Michie, Robert West, and Nigel Harvey}

\section{Susan Michie, ${ }^{1}$ Robert West, ${ }^{2}$ Nigel Harvey ${ }^{3}$}

The concept of fatigue has been used to describe a presumed tendency for people naturally to become tired of the rules and guidance they should follow to prevent the spread of covid-19. ${ }^{1}$ The idea appears to be gaining currency and has been referred to as "behavioural fatigue," "pandemic fatigue," "emergency fatigue," "public fatigue," and "adherence fatigue." A Google search for "pandemic fatigue" resulted in around 200 million hits, with articles on the first page with titles such as " 10 reasons why pandemic fatigue could threaten global health," and "Europe experiencing pandemic fatigue." The question is whether the concept of fatigue accurately captures what is happening. This is important because it affects policies aimed at maximising adherence.

Outside of covid-19, the term fatigue has three main uses. One is a subjective feeling of mental or physical tiredness, which can be caused by mental or physical exertion, sustained activity, lack of sleep, or a health condition. It is a common symptom of covid-19 and of diseases such as cancer. ${ }^{23}$ It is also found in healthy people as part of daily living. The exhaustion may be accompanied by reduced motivation to engage in particular tasks.

Another use of "fatigue" is an impaired ability to perform a mental or physical task as a result of depleted mental or physical resources. This is well studied in endurance sports and tasks that require sustained mental effort. ${ }^{1}$ In this usage, loss of motivation could occur as a result but would not necessarily be expected.

A third use of the term is distress resulting from prolonged exposure to an aversive set of circumstances. ${ }^{4}$ Such distress may have motivational consequences in that the person concerned may want to stop whatever it is that is causing it. It may lead to anger at those perceived as causing it. It may also be accompanied by a feeling of hopelessness and passive acceptance of the situation.

Is there any evidence for fatigue in any of these senses in relation to following covid-19 rules and guidance? We have examined evidence on this from the UK, a country that has suffered more than most from covid-19 and restrictions aimed at combating it.

\section{Is there evidence of declining adherence to rules and guidance?}

Data from surveys are not showing evidence of a continued reduction in adherence to rules and guidance that might be a result of fatigue. For example, in one social study, 5 "majority adherence" has remained high since the start of the lockdown in March. While there was an initial decline in reported "complete adherence," there's been little or no change since July. This is the largest survey of its kind and results are broadly similar to others, including those commissioned by the government. ${ }^{6}$

The decline in complete adherence in late May in England appears to have been exacerbated by a large drop in trust in the government associated with its handling of the "Cummings incident," when the government defended a political adviser who broke social distancing rules. ${ }^{7}$

Reported adherence has been lower in younger people, men, people living with others, key workers, people living with children, people living in cities, and people living in England compared with Wales and Scotland. ${ }^{5}$ Lower adherence to general rules and guidance appears to be related to life circumstances rather than to motivation. ${ }^{8}$

One crucial area of behaviour where adherence is low is self-isolation if one has symptoms, which has been estimated to be around $20 \% .{ }^{9}$ This appears, however, to have been low throughout the pandemic so cannot readily be understood in terms of any factors that are getting worse over time. Evidence suggests that, as with other behaviours, low adherence to the rules around self-isolation may largely be because of people's life circumstances, such as the demands of their work or family life and lack of financial resilience. ${ }^{8} 9$

\section{Is there evidence for decreasing motivation to adhere over time?}

Levels of concern about covid-19 peaked in March and April and then declined and have been steady ever since. ${ }^{10}$ Levels of reported wellbeing increased after the first wave and have remained broadly steady since then. ${ }^{5}$ Consistent with this, levels of anxiety have remained steady in recent months, although feeling stressed specifically about covid- 19 has increased in the past few weeks as infection rates have risen. ${ }^{5}$ Intention to adhere to rules and guidance has remained high throughout the pandemic. ${ }^{10}$

Evidence suggests that the stress associated with financial worries undermines support for policies that are likely to lead to reductions in income or loss of employment. ${ }^{10}$ However, this should not be construed as fatigue. Rather, it can be seen as people resisting hardships that they expect to be forced upon them by circumstances. Concerns about the government's approach and communications may also engender a loss of trust and dwindling 
confidence in the government's position and legitimacy. This could have an impact on future adherence but shouldn't be classed as fatigue. There is also confusion around the rules ${ }^{11}$ and a substantial reduction in the proportion of people who believe that they have the information they need from the government. ${ }^{10}$ Again, these may all negatively affect adherence, but if they did it would not be a matter of fatigue.

Overall, in the UK, we have not yet seen evidence for the kind of decreasing trend in compliance with regulations that could be construed as fatigue, but there are substantial capability, opportunity, and motivational factors that could be contributing to lower levels of adherence than are needed to prevent the spread of the virus. A recent report by the World Health Organization has made a good start on suggesting ways of tackling this-even though the framing of the report was couched in terms of "pandemic fatigue." 12

Declaration of interests: None declared

SM and RW are participants in the Scientific Pandemic Influenza Group on Behavioural Science (SPI-B): 2019 Novel Coronavirus (Covid-19).

Role of funding source: SM is affiliated to University College London's Centre for Behaviour Change and the National Institute for Health Research Behaviour Science Policy Research Unit. The views expressed are those of the authors and not necessarily those of any organisation they are affiliated with. The funders played no role in the writing of the manuscript or the decision to submit it for publication.

1 Harvey N. Behavioural fatigue: real phenomenon, naive construct or policy contrivance. Frontiers in Psychology. 2020. www.frontiersin.org/articles/10.3389/fpsyg.2020.589892/abstract.

2 Okuyama T, Akechi T, Kugaya A, et al. Factors correlated with fatigue in disease-free breast cancer patients: application of the Cancer Fatigue Scale. Support Care Cancer 2000;8:215-22. doi: 10.1007/s005200050288 pmid: 10789963

3 Carfi A, Bernabei R, Landi FGemelli Against Covid-19 Post-Acute Care Study Group. Persistent symptoms in patients after acute covid-19. JAMA 2020;324:603-5. doi: 10.1001/jama.2020.12603 pmid: 32644129

4 Aaronson LS, Teel CS, Cassmeyer V, et al. Defining and measuring fatigue. Image J Nurs Sch 1999;31:45-50. doi: 10.1111/j.1547-5069.1999.tb00420.x pmid: 10081212

5 Fancourt D, Bu F, Mak H, Steptoe A. UCL COVID-19 Social Study Results Release 22. https://b6bdcb03-332c-4ff9-8b9d-28f9c957493a.filesusr.com/ugd/3d9db5_636933e8191d4783866c474fab3ca23c.pdf

6 Office for National Statistics. Coronavirus and the social impacts on Great Britain. 2020 www.ons.gov.uk/peoplepopulationandcommunity/healthandsocialcare/healthandwellbeing/bulletins/coronavirusandthesocialimpactsongreatbritain/10july2020.

7 Fancourt D, Steptoe A, Wright L. The Cummings effect: politics, trust, and behaviours during the COVID-19 pandemic. Lancet 2020;396:464-5 doi: 10.1016/S0140-6736(20)31690-1 pmid: 32771083

8 Atchison CJ, Bowman L, Vrinten C, et al. Perceptions and behavioural responses of the general public during the covid-19 pandemic: a cross-sectional survey of UK adults.medRxiv 2020.04.01.20050039 [Preprint]. 2020. DOI:doi: 10.1101/2020.04.01.20050039.

9 Smith LE, Potts HWW, Amlot R, Fear NT, Michie S, Rubin J. Adherence to the test, trace and isolate system: results from a time series of 21 nationally representative surveys in the UK (the COVID-19 Rapid Survey of Adherence to Interventions and Responses [CORSAIR] study).medRxiv 2020.09.15.20191957 [Preprint]. 2020. DOI:doi: 10.1101/2020.09.15.20191957.

10 Smith LE, Potts HWW, Amlot R, Fear NT, Miche S, Rubin J. The covid-19 rapid survey of adherence to interventions and responses [CORSAIR] study. 2020 [unpublished data].

11 Cushion S, Soo N, Kyriakidou M, Morani M. Different lockdown rules in the four nations are confusing the public. London School of Economics and Political Science. 2020. https://blogs.lse.ac.uk/covid19/2020/05/22/different-lockdown-rules-in-the-four-nations-areconfusing-the-public.

12 World Health Organization. Pandemic fatigue: reinvigorating the public to prevent covid-19.2020 https://apps.who.int/iris/bitstream/handle/10665/335820/WHO-EURO-2020-1160-4090655390-eng.pdf. 